\title{
Compreensão da enfermagem sobre o contato pele a pele entre mãe/bebê na sala de parto
}

Understanding of nursing about skin-to-skin contact between mother/baby in the delivery room

Comprensión de la enfermería sobre el contacto piel con piel entre la madre/bebé en la sala de parto

\section{Hanna Louyse Ribeiro e Souza', Flávia Emília Cavalcante Valença Fernandes ${ }^{\text {II }}$, Rejane Cristiany Lins de França Pereira ${ }^{\mathrm{III}}$, Rosana Alves de Melo ${ }^{\mathrm{IV}}$}

\begin{abstract}
Resumo: Objetivo: descrever a compreensão da equipe de enfermagem da sala de parto sobre o contato pele a pele entre a mãe e bebê na primeira hora de vida. Método: estudo descritivo, qualitativo, com profissionais de enfermagem da sala de parto. Os dados foram coletados de agosto a novembro de 2018, por meio de entrevista semiestruturada e analisados pelo método de análise de conteúdo temática. Resultados: foram extraídas três categorias temáticas: Conhecimento da equipe de enfermagem sobre o contato pele a pele na primeira hora de vida; Benefícios e importância do contato pele a pele no pós-parto imediato na visão dos profissionais; Práticas realizadas no pós-parto imediato na sala de parto. Conclusão: os profissionais de enfermagem possuem o conhecimento sobre o contato pele a pele, mesmo que apresentando algumas fragilidades, e ver-se a importância deste conhecimento para o que esse estímulo seja amplamente efetivado nos cuidados à mãe e ao recém-nascido.

Descritores: Equipe de enfermagem; Recém-nascido; Assistência perinatal; Relações mãe-filho
\end{abstract}

Abstract: Objective: to describe the understanding of the nursing team in the delivery room about skin-to-skin contact between mother and baby in the first hour of life. Method: descriptive, qualitative study with nursing professionals in the delivery room. Data were collected from August to November 2018, through semi-structured interviews and analyzed by the thematic content analysis method. Results: three thematic categories were extracted: Knowledge of the nursing team about skin-to-skin contact in the first hour of life; Benefits and importance of skin-to-skin contact in the immediate postpartum period in the professionals' view; Practices performed in the immediate postpartum in the delivery room. Conclusion: nursing professionals have knowledge about skin-to-skin contact, even if some weaknesses, and see the importance of this knowledge for this stimulus to be widely actualized in the care of the mother and newborn.

\footnotetext{
${ }^{I}$ Enfermeira. Especialista em Saúde da Criança. Hospital Dom Malan-Gestão IMIP Hospitalar. Petrolina, Pernambuco, Brasil. E-mail: hannalrssouza@outlook.com. Orcid: https://orcid.org/0000-0001-8833-2381

II Enfermeira. Doutora em Inovação Terapêutica. Universidade de Pernambuco, Campus Petrolina. Petrolina, Pernambuco, Brasil. E-mail: flavia.fernandes@upe.br. Orcid: https://orcid.org/0000-0003-2840-8561.

III Enfermeira. Especialista em Enfermagem Neonatal e Pediátrica. Hospital Dom Malan-Gestão IMIP Hospitalar. Petrolina, Pernambuco, Brasil. E-mail: rejanelinsf@gmail.com. Orcid: https://orcid.org/0000-0001-5684-3312.

IV Enfermeira. Doutora em Inovação Terapêutica. Universidade Federal do Vale do São Francisco. Petrolina, Pernambuco, Brasil. E-mail: rosananurse@hotmail.com. Orcid: https://orcid.org/0000-0001-9217-921X.
} 
Compreensão da enfermagem sobre o contato pele a pele entre mãe/bebê na sala de parto | 2

Descriptors: Nursing, team; Infant, newborn; Perinatal care; Mother-child relations

Resumen: Objetive: describir la comprensión del equipo de enfermería en la sala de partos sobre el contacto piel con piel entre la madre y el bebé en la primera hora de la vida. Método: estudio descriptivo y cualitativo con profesionales de enfermería en la sala de partos. Los datos fueron recogidos de agosto a noviembre de 2018, a través de entrevistas semiestructuradas y analizados por el método de análisis de contenido temático. Resultados: se extrajeron tres categorías temáticas: Conocimiento del equipo de enfermería sobre el contacto piel con piel en la primera hora de la vida; Beneficios e importancia del contacto piel con piel en el período posparto inmediato de acuerdo con los profesionales; Prácticas realizadas en el posparto inmediato en la sala de partos. Conclusión: los profesionales de enfermería tienen conocimientos sobre el contacto piel con piel, incluso si presentan algunas debilidades, y ven la importancia de este conocimiento para el cual este estímulo se ve ampliamente realizado en el cuidado de la madre y el recién nacido.

Descriptores: Grupo de enfermería; Recién nacido; Atención perinatal; Relaciones madre-hijo

\section{Introdução}

O parto e a assistência ao parto passaram por diversas transformações no decorrer do tempo. Na humanidade, a separação rotineira do binômio mãe/bebê no pós-parto imediato é considerada uma prática do século XX. No entanto, esta diverge dentro da própria evolução histórica, em que a sobrevivência neonatal dependia do contato materno imediato e contínuo com o recém-nascido $(\mathrm{RN}){ }^{1}$

Embora o contato pele a pele precoce seja considerado uma prática evolutiva adequada, separar o RN de sua mãe logo após o nascimento tornou-se uma conduta comum em muitas sociedades industrializadas devido a hospitalização do parto e adesão a práticas rotineiras, impossibilitando um melhor vínculo mãe-bebê. ${ }^{1} \mathrm{O}$ contato pele a pele na primeira hora de vida do RN saudável é o contato imediato e contínuo, no qual esse RN é colocado sobre o abdômen ou tórax da mãe de acordo com sua vontade, de bruços e coberto com um tecido seco e aquecido, ${ }^{2}$ sendo esse contato recomendado pela Sociedade Brasileira de Pediatria (SBP) ${ }^{3}$ quando o RN nasce em boas condições de vitalidade.

O Ministério da Saúde (MS) também incentiva o estabelecimento dessa prática, possibilitando a humanização da assistência materno-infantil, junto às determinações do 
Programa de Humanização no Pré-natal e Nascimento (PHPN) e da Rede Cegonha, que defendem que a mulher e o bebê devem receber boas práticas de atenção. Assim, deve-se garantir a permanência do RN ao lado da mãe durante todo o tempo de internação, desde os primeiros momentos de vida, com contato pele a pele e apoio à amamentação, se possível ainda na primeira hora de vida. ${ }^{4}$

A Organização Mundial de Saúde (OMS) e o Fundo das Nações Unidas para a Infância (UNICEF), com o objetivo de aumentar as taxas e os benefícios do Aleitamento Materno, idealizaram em 1990 a Iniciativa Hospital Amigo da Criança (IHAC), sendo implantada no Brasil em 1992. Isso inclui hospitais que devem seguir critérios globais mínimos instituídos, que estão consubstanciados nos “dez passos para o sucesso do Aleitamento Materno”. Dentre estes, encontra-se o quarto passo, que consiste em "colocar o bebê em contato pele a pele com a mãe imediatamente após o parto, por no mínimo uma hora e encoraja-las a reconhecerem quando seus bebês estão prontos para serem amamentados..$^{5-6}$

Neste contexto, o papel desempenhado pela equipe de enfermagem é primordial, por estes profissionais prestarem assistência na sala de parto vinte e quatro horas por dia, e serem facilitadores do vínculo entre mãe e bebê na transição entre o mundo intra e extrauterino. Além disso, a proposta de humanização na assistência ao parto e nascimento preconiza que esses profissionais estimulem essa aproximação no pós-parto imediato, em contato pele a pele, ${ }^{7}$ colocando o RN sobre o seu tórax, fazendo o clampeamento tardio do cordão umbilical, incentivando a amamentação e fornecendo orientações as mães. ${ }^{8}$

Diante do exposto, evidencia-se a importância de se discutir a implementação do contato pele a pele entre o binômio mãe-bebê na primeira hora de vida, o conhecimento e o papel da equipe de enfermagem, atuante no processo de parturição, acerca da realização desta prática. Desse modo, compreender essa experiência se faz importante por favorecer uma assistência 
Compreensão da enfermagem sobre o contato pele a pele entre mãe/bebê na sala de parto | 4

humanizada e acolhedora de acordo com as necessidades apresentadas nesse contexto assistencial.

Assim, este estudo apresenta como questão de pesquisa: Qual a compreensão da equipe de enfermagem da sala de parto sobre o contato pele a pele entre o binômio mãe/bebê na primeira hora de vida? Seu objetivo foi descrever a compreensão da equipe de enfermagem da sala de parto sobre o contato pele a pele entre a mãe e bebê na primeira hora de vida.

\section{Método}

Pesquisa descritiva, de abordagem qualitativa, que permitiu aos pesquisadores trabalhar com os significados, sentimentos, dos motivos, atitudes e percepções dos entrevistados. ${ }^{9}$ A mesma ocorreu em um hospital público de referência na área da assistência materno-infantil, estando localizado no sertão nordestino e serve de suporte para os 55 municípios que compõem a rede Pernambuco/Bahia. Desde agosto de 1995 possui o título de Hospital Amigo da Criança.

O cenário do estudo foi a Sala de Parto da referida instituição, que conta com o apoio de uma equipe multidisciplinar composta por médicos obstetras e pediatras, enfermeiros, técnicos de enfermagem, psicólogos, assistentes sociais, entre outros. A equipe de enfermagem é composta por 19 enfermeiros e 20 técnicos de enfermagem. Foram participantes da pesquisa 13 profissionais da equipe de enfermagem, sendo oito enfermeiras e cinco técnicas de enfermagem, que atendessem aos seguintes critérios de seleção: serem profissionais enfermeiros e/ou técnicos de enfermagem da sala de parto; que não estivessem de férias ou em qualquer tipo de licença no período de realização da coleta dos dados.

O número de participantes foi definido pela saturação teórica dos dados, em que o processo de coleta é encerrado quando as informações obtidas não trazem novos elementos que aprofundem ou subsidiem a teorização pretendida diante dos objetivos do estudo. ${ }^{9}$ 
A coleta de dados deu-se nos meses de agosto a novembro de 2018, com aplicação de entrevista semiestruturada, composta inicialmente por dados sociodemográficos e as seguintes questões norteadoras: Falar sobre os cuidados realizados no pós-parto imediato ao RN na sala de parto; Descrever as boas práticas que devem ser realizadas durante o pós-parto imediato com o RN; Descrever o entendimento por contato pele a pele precoce entre a mãe e o bebê; Falar sobre a importância/benefício para mãe e bebê do contato pele a pele na primeira hora de vida; Relatar as contraindicações para realização do contato pele a pele precoce da mãe e bebê; Citar as dificuldades existentes que evitam a realização do contato pele a pele entre mãe e bebê, mesmo quando indicado.

As entrevistas foram realizadas com uso de gravador portátil, após autorização do participante, em local e horário previamente estabelecidos de acordo com a sua disponibilidade, após rigoroso treinamento das pesquisadoras, de forma a viabilizar o andamento do processo e não permitir a perda de informações importantes para a conclusão da pesquisa. Essa etapa de coleta dos dados durou em média 20 minutos por entrevista. Para preservar o anonimato das participantes, foram atribuídos códigos identificadores, de acordo com a sequência em que foram entrevistadas (E1, E2, E3... E13).

Todos os participantes foram informados sobre os objetivos, metodologia, riscos e benefícios do estudo. As entrevistas foram iniciadas após leitura e assinatura do Termo de Consentimento Livre e Esclarecido, logo após foram transcritas e revisadas após escuta exaustiva das gravações. Os dados foram analisados por meio da Análise de Conteúdo Temática, que foi processada a partir de três etapas distintas: pré-análise, em que o material empírico foi organizado e envolveu a transcrição, na íntegra, do material áudio gravado, realizado após cada entrevista. A partir da transcrição do material, foi realizada leitura exaustiva do material, buscando organizá-lo conforme similaridades das falas e outros aspectos relevantes trazidos 
Compreensão da enfermagem sobre o contato pele a pele entre mãe/bebê na sala de parto 6

pelos entrevistados, de acordo com o tema geral desta pesquisa, configurando-se como uma préanálise do corpus. ${ }^{9}$

A segunda etapa, constituída pela exploração do material, compreendeu a categorização das falas, que serviu para o avanço na análise temática do material. Priorizou-se os sentidos a respeito da visão da equipe de enfermagem e do contato pele a pele entre o binômio mãe/bebê na primeira hora de vida, segundo os objetivos propostos. A terceira e última etapa foi o tratamento dos resultados com interpretações dos dados, que teve como finalidade tratar o material investigado por meio da codificação, classificação e interpretação, resultando nas categorias de análise. ${ }^{9}$

O presente estudo segue todos os aspectos de pesquisa de acordo com a Resolução no 466/12 do Conselho Nacional de Saúde, tendo sido aprovado pelo Comitê de Ética em Pesquisa com seres humanos do Instituto de Medicina Integral Professor Fernando Figueira em 11 de julho de 2018, sob número do parecer 2.766.197 e CAAE 90824718.5.0000.5201.

\section{Resultados e discussão}

As participantes da pesquisa eram todas do sexo feminino, sendo oito enfermeiras e cinco técnicas de enfermagem. Das enfermeiras entrevistadas, seis eram especialistas em obstetrícia; uma estava cursando especialização em enfermagem obstétrica e era especialista em urgência e emergência; e uma não tinha especialização. Com relação a idade, seis encontravam-se na faixa etária entre 24 e 28 anos; seis tinham entre 30 e 35 anos, e uma delas tinha idade de 57 anos.

Quanto ao tempo de profissão, três delas estavam atuando na enfermagem entre um e dois anos; seis atuavam de três a cinco anos; três de seis a 10 anos, e uma tinha 20 anos de atuação profissional. No tocante ao tempo de prestação de serviço na sala de parto, três tinham menos de um ano de atuação no setor; cinco atuavam de um a dois anos; e cinco delas de três a cinco anos. Com relação a participação em treinamentos e/ou capacitações que abordassem o 
tema da pesquisa, dez afirmaram ter participado em algum momento de capacitação que falou sobre o contato pele a pele no binômio mãe e filho; e três não participaram de nenhuma abordagem sobre a temática, no entanto, uma delas afirmou já ter recebido orientações a este respeito na própria sala de parto.

Após leitura exaustiva dos relatos encontrados e da busca de núcleos de sentido, foram extraídas três categorias temáticas que serão abordadas a seguir:

\section{Conhecimento da equipe de enfermagem sobre o contato pele a pele na primeira hora de vida}

O contato pele a pele imediato e contínuo realizado entre a mãe e o bebê na primeira hora do pós-parto imediato, possui o objetivo de melhorar o período de adaptação do RN e da mãe na transição do espaço intra para o extrauterino. ${ }^{2,10}$ Nessa perspectiva, as participantes mostraram um entendimento adequado a respeito dessa técnica:

No pós-parto imediato, se estiver tudo bem, deixa pelo menos uma hora em cima da mãe, para que ele se normalize [...]. (E3)

[...] contato pele a pele a gente retira logo o bebê e coloca em cima da mãe, em contato direto. (E6)

[...] saiu do útero vai direto para a mãe, o pele a pele mesmo, o bebê peladinho em cima da mãe, entre os peitos da mãe. (E11)

Esses depoimentos corroboram com os achados evidenciados em pesquisas de abordagem similar, realizadas com profissionais da equipe de enfermagem, nas quais os pesquisadores concluíram que a equipe mostrou ter um bom conhecimento científico sobre as práticas de humanização realizadas na sala de parto, incluindo o contato pele a pele na primeira hora de vida. $^{7-8}$

Quando questionadas sobre a indicação da realização do contato pele a pele, as participantes trouxeram diversas considerações com relação as indicações e contraindicações, por exemplo, o escore de Apgar, a presença de mecônio e a prematuridade. 
Compreensão da enfermagem sobre o contato pele a pele entre mãe/bebê na sala de parto $\mid 8$

Caso o bebê não nasça com uma boa vitalidade, prematuridade e um Apgar baixo, aí tem que dar os cuidados imediatos. (E5)

A gente realiza com os bebês de baixo risco [...]. O RN com mecônio, batimentos cardíacos abaixo de 120 [...] geralmente faz o estímulo e já vai clampear logo o cordão e dar os cuidados. (E6)

É indicado quando o bebê é termo e nasce com boa vitalidade. E a gente não deve deixar quando é prematuro e necessita de cuidados mais específicos. (E8)

As contraindicações orientadas pelo MS e a SBP passaram por atualizações e compreendem a apresentação do RN com a idade gestacional diferente do termo; a ausência do início dos movimentos respiratórios regulares do $\mathrm{RN}$ e/ou aqueles em que o tônus muscular está flácido, sendo que, nestes casos, devem ser conduzidos à mesa de reanimação e a equipe deve seguir o fluxograma do Programa de Reanimação da SBP. ${ }^{2-3}$

No ano de 2016 a nova diretriz de reanimação da SBP, considerando o RN $\geq 34$ semanas, nascido em sala de parto, trouxe atualizações que refletem na indicação e contraindicação da realização do contato pele a pele precoce entre mãe e filho, retificando a portaria n $371 / 2014$, que contraindica a realização do contato pele a pele precoce na presença de líquido meconial. ${ }^{3}$ Esta mudança foi reafirmada pelo MS por meio das novas diretrizes nacionais de assistência ao parto normal em 2017. ${ }^{11}$

Considerando o boletim de Apgar como forma de avaliar a indicação da realização do contato pele a pele indicado por algumas participantes, ressalta-se que este boletim corresponde a uma avaliação clínica do $\mathrm{RN}$, o qual avalia cinco aspectos do neonato: tônus muscular, frequência cardíaca, esforço respiratório, irritabilidade reflexa e coloração da pele. Para cada um dos desses itens é atribuída uma nota 0,1 ou 2 que somando-se o escore de cada item se obtém um mínimo de 0 e máximo de 10 pontos. Desta forma, o boletim de Apgar não é utilizado para indicar procedimentos na reanimação neonatal ou vitalidade do RN. No entanto, sua aplicação permite avaliar alguns dados da avaliação da vitalidade, como a respiração e o tônus muscular. . $^{3,12}$ 
Ademais, ressalta-se que, para que esse contato possa ser instituído com êxito, é necessário que mãe e bebê estejam em alerta do ponto de vista neurológico, interagindo naturalmente. Assim, é primordial que o contato pele a pele ocorra precocemente, logo após o nascimento, uma vez que em algumas horas após o parto os neonatos se mantêm sonolentos. ${ }^{10}$

Além das observações citadas em relação ao RN, uma das profissionais entrevistadas citou o teste rápido anti-HIV reagente, como uma contraindicação relacionada a genitora.

Colocar para mamar na primeira hora de vida, isso se os testes rápidos forem não reagentes, o do HIV que faz na triagem. (E9)

O relato da participante coaduna com aquilo que é recomendado pelo Protocolo Clínico e Diretrizes Terapêuticas para Manejo da Infecção pelo HIV em Crianças e Adolescentes. O contato pele a pele não deve ser indicado na primeira hora de vida devido ao manejo do RN exposto ao HIV, que é indicado a realização de cuidados específicos após o nascimento a fim de garantir a prevenção da transmissão vertical do vírus, sendo o RN colocado junto à mãe o mais brevemente possível após os cuidados. ${ }^{13}$

Benefícios e importância do contato pele a pele no pós-parto imediato na visão dos profissionais

De acordo com as participantes, o contato pele a pele entre o binômio mãe-filho proporciona vários benefícios, como formação do vínculo e adaptação fisiológica do RN, além de ser importante na transição do período do parto e nascimento, tanto para o RN quanto para a genitora.

Aumentar o sentimento, laço afetivo [...]. Para o bebê, diminui a frequência cardiaca, uma maneira dele se acalmar [...]. Também estimula o aleitamento materno [...]. (E3)

Eu acho que para a mãe no momento que ela tem o contato com o bebê a ansiedade dela acaba. Para o bebê, temos a questão do aquecimento, do fortalecimento do vínculo. (E4)

Para o bebê vem a parte do aquecimento, vai estabilizar a respiração dele também. (E7) 
Compreensão da enfermagem sobre o contato pele a pele entre mãe/bebê na sala de parto | 10

A visão das participantes com relação aos benefícios se mostrou coerente e corrobora com os dados descritos na literatura, no que concerne à enorme gama de benefícios para ambos, em curto e longo prazo, além da organização do estado comportamental do RN.1,14

Outro estudo realizado com membros da equipe multiprofissional de sala de parto, corroborou com os achados desta pesquisa com relação aos benefícios evidenciados pelas participantes, destacando que existem inúmeros benefícios imediatos dessa técnica para a puérpera e para o neonato, tais como estabelecimento do vínculo, regulação da temperatura corporal do RN, adaptação fisiológica do neonato e estímulo a amamentação. ${ }^{15}$

Segundo a OMS e UNICEF, ${ }^{16}$ o contato pele a pele precoce é capaz de: acalmar a mãe e o RN, auxiliar na estabilização sanguínea, dos batimentos cardíacos e respiração do bebê; reduzir o choro e o estresse do RN com menor perda de energia; manter a criança aquecida pela transmissão de calor da genitora; auxiliar na adaptação metabólica e a estabilização da glicose sanguínea do neonato; permitir a colonização do intestino do bebê com as bactérias normais do intestino da mãe, contanto que ela seja a primeira pessoa a segurar o $\mathrm{RN}$; facilitar o estreitamento dos vínculos afetivos entre o binômio mãe e filho, ajudando no estímulo ao aleitamento materno, com uma probabilidade de resultar em uma sucção efetiva. ${ }^{14,16-17}$

Ainda quando questionadas sobre a importância do contato pele a pele, pode-se observar que a maioria das participantes fazem uma correlação direta entre a sua realização apenas como uma forma promover a amamentação de forma isolada aos demais procedimentos:

É o contato para que haja a questão da amamentação na primeira hora de vida do bebê. (E3)

No momento que o bebê nasce já coloca ele sobre a mãe [...] a questão de promover a amamentação. (E4)

Assim que ele nasce coloca no contato pele a pele, [...] para mamar, realizar a sucção. (E12) 
Ademais, um estudo de metanálise mostrou que o contato pele a pele precoce entre mãe e filho tem efeito bastante positivo sobre a amamentação, na adequação do nível de glicose no sangue dos RN nas primeiras horas de vida, além de ajudar na estabilidade cardiorrespiratória do mesmo. ${ }^{18}$ Entretanto, vale ressaltar que, a realização deste contato apresenta-se como um procedimento de comprovados benefícios no curto e no longo prazo, para as mães e as crianças, e não só apenas relacionado a amamentação. ${ }^{1,18}$

Observou-se em alguns depoimentos a relação entre o contato pele a pele e as alterações fisiológicas e hormonais que acontece com a genitora ao amamentar o RN, além de ajudar na prevenção de possíveis complicações, corroborando com os achados de outro estudo, que também evidenciou as vantagens decorrentes da amamentação para a própria saúde das mães. ${ }^{19}$

É importante para evitar a hemorragia materna [...] prevenção da anemia [...]. (E1)

Para a mãe vai ajudar a desenvolver mais leite, [...], vai produzir mais hormônios [ocitocina] que vai ajudar até a diminuir o sangramento. (E7)

Para a mãe, quando o bebê começa a mamar, vai ter a involução do útero, que vai livrar a mãe de hemorragia [...]. (E13)

O contato pele a pele entre mãe e bebê na primeira hora de vida é uma das estratégias utilizadas pelo MS que visa a promoção, proteção e apoio ao aleitamento materno e se baseia na capacidade de interação dos RN com suas mães, logo após o nascimento., ${ }^{2,6}$ Além de estar relacionado com o aumento da duração da amamentação e do aleitamento materno exclusivo. ${ }^{20}$

Segundo um estudo controlado e não randomizado, realizado em uma sala de parto com 100 mulheres para avaliar os efeitos do contato pele a pele imediato, a realização desta prática aumenta a contração uterina imediatamente após o nascimento, diminuindo a atonia uterina e perda excessiva de sangue. Além de diminuir significativamente a duração do terceiro estágio do trabalho de parto. ${ }^{21}$ 
Uma das entrevistadas também referiu uma relação na prevenção de infecções quando é realizado o contato pele a pele na primeira hora de vida.

Para o bebê o contato com a mãe faz com que ele se aqueça e se tranquilize. Protege contra infecção também. (E10)

A literatura aborda que um dos benefícios da realização do contato pele a pele é a proteção contra infecções, uma vez que facilita a colonização da pele do RN pela flora bacteriana da pele materna, previamente ao contato com as bactérias hospitalares, ajudando a prevenir infeções, além de estimular e aleitamento materno que possui funções antimicrobianas, anti-inflamatórias e imunorreguladores. Tudo isso, ajuda na transferência de imunidade passiva no período pós-natal. ${ }^{16,22}$

\section{Práticas realizadas no pós-parto imediato na sala de parto}

Quando perguntadas sobre quais são os cuidados imediatos oferecidos aos RN na sala de parto, as participantes incluíram o contato pele a pele como um dos primeiros a serem realizados após o nascimento. No entanto, algumas delas só citaram essa técnica quando indagadas sobre as boas práticas:

Na hora que nasce a gente coloca ele em cima da mãe, uma hora depois o pediatra pega e faz a ausculta do bebê, pesa, mede e faz o método do credé. (E2)

No pós-parto imediato é feito no $R N$ a pesagem, vitamina $K$, o credé, as medicações. Como boas práticas, se ele estiver bem, não tiver nenhuma intercorrência, deixa em cima da mãe e é feito o clampeamento [...]. (E3)

Logo quando o RN nasce, a gente aquece o bebê, coloca sobre a mãe e deixa ali, no período de uma hora. O clampeamento do cordão é feito, depois é levado o bebê para o berço aquecido, onde vai ser prestado os cuidados. (E8)

Esses achados se mostram bastante recorrentes em diversas realidades, em que, primeiramente, é proporcionado o contato pele a pele para depois seguir os cuidados imediatos, 
como a higiene do RN. Mostra-se necessário o conhecimento do que é preconizado pela Política de Humanização ao Pré-natal e Nascimento, no que concerne aos cuidados imediatos com o RN após o nascimento. ${ }^{4}$

Quando o RN nasce com boa vitalidade, deve-se cobrir a criança com um campo ou toalha morna para mantê-la aquecida, enquanto mantém o contato pele a pele. Em seguida, realizar o clampeamento do cordão umbilical entre um a cinco minutos, ou de forma fisiológica quando cessar a pulsação. Após pelo menos uma hora de contato pele a pele, realiza-se os demais procedimentos, como a profilaxia da oftalmia neonatal (método do credé). Recomenda-se também que todos os recém-nascidos recebam vitamina $K$ para a profilaxia da doença hemorrágica. Registrar a circunferência cefálica, temperatura corporal e peso após a primeira hora de vida, dentre outros..$^{2-3,11,15}$

Ao nascer, o RN passa por uma fase denominada inatividade alerta, com duração média de quarenta minutos, na qual se preconiza a redução de procedimentos de rotina, em RN de baixo risco. Nesta fase, o contato mãe-filho deve ser proporcionado, por tratar-se de um período de alerta que favorece o reconhecimento das partes, ocorrendo a exploração do corpo da mãe pelo bebê. ${ }^{10}$

Em contrapartida, muitos profissionais elencaram alguns empecilhos para a facilitação do contato pele a pele, trazendo a grande demanda do setor e a má vontade de alguns pediatras como os principais entreves para sua efetivação.

Os pediatras querem tirar logo, rápido, para poder dar os cuidados, às vezes nem deixam. (E1)

Tem dificuldade pela questão de ter muitos partos ao mesmo tempo. [...] Deixa só uns 10, 15 minutos e já pega logo para dar os cuidados. (E8)

Tem pediatra que quer logo agilizar seu processo e pega o RN, pede para clampear e a gente clampea e eles levam [...] mas tem outros poucos que segue o quarto passo. (E9) 
Compreensão da enfermagem sobre o contato pele a pele entre mãe/bebê na sala de parto | 14

A demanda, a quantidade de pacientes [...] aí a gente pega a criança, faz os procedimentos e só depois devolve para a mãe[...]. (E13)

Os profissionais atuantes nos cenários de parto e nascimento são essenciais para que seja estimulado o contato precoce entre a mãe e o bebê, podendo agir como facilitadores desses processos. ${ }^{7,23}$ No entanto, estudos ${ }^{10,15,24}$ mostram a existência de inconformidades na atuação dos profissionais quanto à promoção do contato precoce na sala de parto. Por vezes, os profissionais da equipe multiprofissional provocam a separação do binômio mãe/bebê, devido barreiras institucionais como a alta demanda da rotina hospitalar, corroborado com os resultados encontrados neste estudo.

Autores enfatizam que a busca por agilidade nas rotinas hospitalares, a dinamização do turno de trabalho e a alta produtividade, muitas vezes, acabam levando os profissionais a prestarem uma assistência fragmentada e mecanicista, distanciando-os dos preceitos estabelecidos pela IHAC e pelo MS. ${ }^{10,15,24}$ Nesse sentido, outros autores afirmam que essas justificativas não deveriam ser um impeditivo à implementação do cuidado humanizado ao RN na sala de parto, uma vez que o contato pele a pele é uma técnica de fácil execução e baixo custo, e tem inúmeros benefícios. ${ }^{18}$

Nesse contexto, outras profissionais referiram não existir dificuldades para a realização do contato pele a pele entre mãe-bebê, e que só não é realizado na rotina do serviço se não houver indicação clínica, atribuindo às capacitações realizadas na instituição, como responsável pela manutenção das condutas corretas no setor.

Dificuldade aqui no setor, agora mais não. Foi feito um trabalho junto com alguns pediatras e assim, agora a equipe está bem coesa nessa questão. (E3) Aqui na sala de parto, se os bebês puderem ficar com a mãe, os pediatras deixam sem nenhum problema. (E7)

A efetivação do modelo de humanização no parto requer a sensibilização e a capacitação constante dos trabalhadores de Centros Obstétricos, sendo necessário a realização de 
treinamentos para a implementação da prática do contato pele a pele. ${ }^{7}$ Assim, ressalta-se que a equipe conhece e acredita nesse cuidado, porém, treinamentos se fazem necessários para a sua implementação, uma vez que a mecanização da assistência e o tempo maior no serviço faz com que muitos profissionais passem a banalizar a assistência prestada, necessitando muitas vezes de processos de educação continuada para atualizar os conhecimentos e repensar a forma de oferta de seus cuidados rotineiros. ${ }^{25}$

Nesse ínterim, as limitações encontradas no desenvolvimento dessa pesquisa, envolveram o fato da realização da coleta de dados ter se dado somente na maternidade de referência materno infantil da região, havendo a importância de se ampliar a pesquisa para demais centros obstétricos locais, de forma a se conhecer a amplitude dessa prática em locais com menor estrutura. Dessa forma, fica a provocação para o desenvolvimento de novos estudos nesta perspectiva em outros locais de assistência ao parto, e que também englobem demais categorias profissionais, a exemplo da medicina, que assistem as mulheres nesse contexto assistencial.

\section{Conclusão}

Este estudo permitiu constatar que a equipe de enfermagem tem o conhecimento do que se configura o contato pele a pele entre o binômio mãe e bebê na primeira hora de vida do RN. Contudo, algumas profissionais mostraram fragilidade no conhecimento sobre as indicações e contraindicações dessa técnica, havendo algumas que realizaram uma correlação direta do contato pele a pele apenas com a amamentação. Evidenciou-se também o conhecimento relativo acerca dos benefícios da realização do contato para o RN e a genitora, uma vez que a maioria das profissionais citaram mais o vínculo e os benefícios ligados a amamentação e a minoria citou os benefícios fisiológicos para o RN.

Relacionados às práticas realizadas no pós-parto imediato, observou-se que a maioria das participantes incluíam o contato pele a pele como cuidado imediato, mas somente quando 
indagadas sobre a realização das boas práticas. Outras entrevistadas citaram a grande demanda de partos e a não adesão por parte de alguns profissionais como barreiras para sua efetivação. Em contrapartida, foi citado que capacitações ajudaram a melhorar a conduta da maior parte da equipe médica, estimulando a realização do contato pele a pele quando indicado.

Nesse contexto, os resultados encontrados são relevantes, visto que a equipe de enfermagem exerce papel fundamental no parto e nascimento e na realização dos cuidados prestados à mãe e ao RN. Desta forma, o conhecimento adequado da equipe é imprescindível para o estímulo e realização de novas práticas estabelecidas nas instituições.

Diante da discussão trazida nessa pesquisa, reitera-se a importância que novos estudos sejam produzidos nessa mesma temática, na perspectiva de estimular a realização desta prática e aumentar os benefícios a curto e longo prazo. Além da necessidade de potencializar, junto aos profissionais, o tema abordado nesse estudo.

\section{Referências}

1. Moore E, Bergman N, Anderson G, Medley N. Early skin-to-skin contact for mothers and their healthy newborn infants. Cochrane Database Syst Rev. 2016;11(3519):1-4. doi: 10.1002/14651858.CD003519.pub4

2. BRASIL. Ministério da Saúde. Portaria no 371, de 07 de maio de 2014. Institui diretrizes para a organização da atenção integral e humanizada ao recém-nascido (RN) no Sistema Único de Saúde (SUS). Diário Oficial da União, seção 1, p. 50, 8 maio 2014.

3. Sociedade Brasileira de Pediatria (SBP). Reanimação do recém-nascido $\geq 34$ semanas em sala de parto: Diretrizes 2016 da Sociedade Brasileira de Pediatria [Internet]. 2016 [acesso em 2019 jan 04]. Disponível em:

http://wwws.sbp.com.br//reanimacao/wpcontent/uploads/2016/01/diretrizessbpreanimacaornmaior34semanas26jan2016.pdf

4. BRASIL. Ministério da Saúde. Portaria no 1.459, de 24 de junho de 2011. Institui, no âmbito do Sistema Único de Saúde - SUS - a Rede Cegonha. Diário Oficial da União, seção 1, p. 109, 27 jun. 2011.

5. World Health Organization (WHO); United Nations Children's Fund (UNICEF). Implementation guidance: protecting, promoting and supporting breastfeeding in facilities providing maternity and newborn services: the revised Baby-friendly Hospital Initiative. Geneva: WHO; 2018 [cited 2018 Dec 21]. Available from: https://apps.who.int/iris/bitstream/handle/10665/272943/9789241513807- 
eng.pdf? sequence $=19 \&$ is Allowed $=y$

6. BRASIL. Ministério da Saúde. Portaria n 1.153, de 22 de maio de 2014. Redefine os critérios de habilitação da Iniciativa Hospital Amigo da Criança (IHAC), como estratégia de promoção, proteção e apoio ao aleitamento materno e à saúde integral da criança e da mulher, no âmbito do Sistema Único de Saúde (SUS). Diário Oficial da União, seção 1, p. 43, 28 maio 2014.

7. Gomes LOS, Andrade LO, Pinheiro ES, Souza FS, Boery RNSO. Practices of nursing professionals against humanized labor. Rev Enferm UFPE On Line [Internet]. 2017 [cited 2018 Dec 21];11(6):2576-85. Available from: https://periodicos.ufpe.br/revistas/revistaenfermagem/article/view/23426

8. Oliveira BS, Batista SG, Valcarenghi RV, Mattos ARS, Correia JBB, Hoffmann ACOS. Contato precoce pele a pele entre mãe e recém-nascido: contribuições da enfermagem em uma maternidade de São José/SC. Rev Estácio Saúde [Internet]. 2020 [acesso em 2020 abr 17];9(1):8-16. Disponível em: http://revistaadmmade.estacio.br/index.php/saudesantacatarina/article/view/6034/47966442

9. Minayo MCS, Deslandes FS, Gomes R. Pesquisa social: teoria, método e criatividade. Rio de Janeiro (RJ): Vozes; 2016.

10. Santos LMS, Silva JCR, Carvalho ESS, Carneiro AJS, Santana RCB, Fonseca MCC. Vivenciando o contato pele a pele com o recém-nascido no pós-parto como um ato mecânico. Rev Bras Enferm. 2014;67(2):202-7. doi: 10.5935/0034-7167.20140026

11. Ministério da Saúde (BR). Diretrizes nacionais de assistência ao parto normal: versão resumida [Internet]. Brasília (DF): Ministério da Saúde; 2017 [acesso em 2019 fev 20]. Disponível em: http://bvsms.saude.gov.br/bvs/publicacoes/diretrizes_nacionais_assistencia_parto_normal.pdf

12. Muniz EB, Vasconcelos BB, Pereira NA, Frota RG, Moraes CEB, Oliveira MAS. Análise do boletim de Apgar em dados do Sistema de Informação sobre Nascidos Vivos registrados em um hospital do interior do estado do Ceará, Brasil. Rev Med Saúde Brasília [Internet]. 2016 [acesso em 2019 jan 22];5(2):182-91. Disponível em: https://portalrevistas.ucb.br/index.php/rmsbr/article/view/6677

13. Ministério da Saúde (BR). Protocolo Clínico e Diretrizes Terapêuticas para Manejo da Infecção pelo HIV em Crianças e Adolescentes [Internet]. Brasília (DF): Ministério da Saúde, Departamento de Doenças de Condições Crônicas e Infecções Sexualmente Transmissíveis; 2018 [acesso em 2018 nov 20]. Disponível em: http://www.aids.gov.br/pt-br/pub/2017/protocolo-clinico-e-diretrizes-terapeuticas-paramanejo-da-infeccao-pelo-hiv-em-criancas-e

14. Dani C, Cecchi A, Commare A, Rapisardi G, Breschi R, Pratesi S. Behavior of the newborn during skin-to-skin. J Hum Lact. 2015;31(3):452-7. doi: 10.1177/0890334414566238

15. Kologeski TK, Strapasson MR, Schneider V, Renosto JM. Skin to skin contact of the newborn with its mother in the perspective of the multiprofessional team. Rev Enferm UFPE On Line [Internet]. 2017 [cited Nov 2018;11(1):94-101. Available from: 
https://periodicos.ufpe.br/revistas/revistaenfermagem/article/view/11882

16. World Health Organization (WHO); United Nations Children's Fund (UNICEF). Baby-Friendly Hospital Iniciative: revised, updated and expanded for integrated care. Section 3: breastfeeding promotion and suport in a Baby-friendly hospital: a 20-hour course for maternity staff. Geneva: 2009 $\begin{array}{lllll}\text { [cited } & \text { Feb } & 2018 & 02\end{array}$ from: https://www.who.int/nutrition/publications/infantfeeding/bfhi_trainingcourse_s3/en/

17. Kim BY. Factors that influence early breastfeeding of singletons and twins in Korea: a retrospective study. Int Breastfeed J. 2017;12:4(2016). doi: 10.1186/s13006-016-0094-5

18. Sampaio ARR, Bousquat A, Barros C. Skin-to-skin contact at birth: a challenge for promoting breastfeeding in a "Baby Friendly" public maternity hospital in Northeast Brazil. Epidemiol Serv Saúde [Internet]. 2016 [cited 2018 Nov 09];25(2):281-90. Available from: https://www.scielo.br/scielo.php?script=sci_arttext\&pid=S2237-

96222016000200281\&lng=en\&nrm=iso\&tlng=en

19. Martins MZO, Santana LS. Benefícios da amamentação para saúde materna. Interfaces Cient Saúde Ambiente. 2013;1(3):87-97. doi: 10.17564/2316-3798.2013v1n3

20. Silva CM, Pereira SCL, Passos IR, Santos LC. Fatores associados ao contato pele a pele entre mãe/filho e amamentação na sala de parto. Rev Nutr (Online). 2016;29(4):457-71. doi: https://doi.org/10.1590/1678-98652016000400002

21. Essa RM, Ismail NIAA. Effect of early maternal/newborn skin-to-skin contact after birth on the duration of third stage of labor and initiation of breastfeeding. J Nurs Educ Pract. 2015;5(4):98-107. doi: 10.5430/jnep.v5n4p98

22. Gura T. Nature's first functional food. Science. 2014;345(6198):747-9. doi: https://doi.org/10.1126/science.345.6198.747

23. Fucks IS, Soares MC, Kerber NPC, Meincke SMK, Escobal APL, Bordignon SS. Sala de parto: o contato pele a pele e as ações para o estímulo ao vínculo entre mãe-bebê. Av Enferm. 2015;33(1):29-37. doi: http://dx.doi.org/10.15446/av.enferm.v33n1.47371

24. Koopman I, Callaghan-Koru JA, Alaofin O, Argani CH, Farzin A. Early skin-to-skin contact for healthy full-term infants after vaginal and caesarean delivery: a qualitative study on clinician perspectives. J Clin Nurs. 2016; 25(9-10):1367-76. doi: https://doi.org/10.1111/jocn.13227

25. Vittner D, Cong X, Ludington-Hoe SM, McGrath JM. A survey of skin-to-skin contact with perinatal nurses. Appl Nurs Res. 2017;33(1):19-23. doi: https://doi.org/10.1016/j.apnr.2016.09.006 
Editor Científico Chefe: Cristiane Cardoso de Paula

Editor Associado: Aline Cammarano Ribeiro

\section{Autor correspondente}

Rosana Alves de Melo

E-mail: rosananurse@hotmail.com.

Endereço: Avenida José de Sá Maniçoba, S/N, Centro. Petrolina, Pernambuco, Brasil.

CEP: 56304-917

\section{Contribuições de Autoria}

\section{1 - Hanna Louyse Ribeiro e Souza}

Participou da concepção e planejamento do projeto de pesquisa, obtenção ou análise e interpretação dos dados, redação e revisão crítica.

\section{2 - Flávia Emília Cavalcante Valença Fernandes}

Participou da concepção e planejamento do projeto de pesquisa, análise e interpretação dos dados, e revisão crítica.

\section{3 - Rejane Cristiany Lins de França Pereira}

Participou da concepção e planejamento do projeto de pesquisa, obtenção ou análise e interpretação dos dados, e revisão crítica.

\section{4 - Rosana Alves de Melo}

Participou da concepção e planejamento do projeto de pesquisa, obtenção ou análise e interpretação dos dados, redação e revisão crítica.

\section{Como citar este artigo}

Souza HLR, Fernandes FECV, Pereira RCLF, Melo RA. Compreensão da enfermagem sobre o contato pele a pele entre mãe/bebê na sala de parto. Rev. Enferm. UFSM. 2020 [Acesso em: Anos Mês Dia]; vol.10 e93: 1-19. DOI: https://doi.org/10.5902/2179769242729 